\title{
Prática pedagógica e o conhecimento declarativo de alunos do Ensino Fundamental II sobre a Cultura de Movimento
}

\author{
Maurício Teodoro de Souza* \\ Andréa Cristina Saitsu** \\ Roberto Gimenez ${ }^{* * *}$
}

\begin{abstract}
Resumo
O presente estudo objetivou analisar o contexto escolar no qual o professor de educação física utilizou a orientação dos referenciais curriculares do estado de São Paulo identificando os impactos da prática pedagógica sobre o conhecimento dos alunos do ensino fundamental II. Participaram desta pesquisa 52 jovens. Os procedimentos caracterizaram-se por pesquisa bibliográfica e exploratória. A técnica de Survey foi utilizada no levantamento e agrupamento das informações. Os resultados encontrados sugerem uma ampliação da visão sobre o componente curricular Educação Física, a qual é reforçada pela menção de temas como pessoas com deficiência, questões étnico-raciais e pela apropriação de espaços públicos.
\end{abstract}

Palavras-chave: Educação Física; Ensino Fundamental II; Prática Pedagógica; Conhecimento Declarativo.

Pedagogical practice and the declarative knowledge of elementary school students on Physical Education

\begin{abstract}
The present study aimed at analyzing the school context in which the physical education teacher used the orientation of the curricular references of the state of São Paulo, identifying the impacts of the pedagogic practice on the knowledge of the elementary school students II. Fifty-two young people participated in this study. The procedures were characterized by bibliographic and exploratory research. The Survey technique was used in the collection and grouping of information. The results suggest a broader view of the Physical Education curriculum component, which is reinforced by the mention of subjects such as people with disabilities, ethnicracial issues and the appropriation of public spaces.

Keywords: Physical Education; Elementary School; Pedagogical Practice; Declarative Knowledge.
\end{abstract}

\section{Introdução}

Há anos ocorrem debates em torno do papel da Educação, especialmente uma reflexão sobre a efetiva contribuição para o projeto da escola, bem como, sobre a natureza do conhecimento, seja ele procedimental, atitudinal ou conceitual. Medina, Megías e Arcos (2013) afirmam que os debates sobre Educação possuem mais preocupação com os meios de como fazer do que as finalidades, ou seja, para que fazer. Se perguntados sobre a finalidade da educação física poucos alunos responderiam formar-se como pessoas, como cidadãos.

Tendo em vista a nova demanda social de abordar situações de práticas educativas, há necessidade de enfrentarmos um processo de formação pautado em uma perspectiva integral e de desenvolvimento humano. $\mathrm{O}$ protagonismo, a diversidade, a individualidade dos alunos são os aspectos importantes de uma educação que visa construir e reconstruir a realidade social.

Os próprios professores podem buscar esse

\footnotetext{
* Endereço Eletrônico: mauricio.teodoro@ terra.com.br

*** Endereço Eletrônico: deiasaitsu@ hotmail.com

**** Endereço Eletrônico: roberto.gimenez@unicid.edu.br
}

princípio de reinventar-se considerando as novas responsabilidades sociais, as quais pedem $\mathrm{o}$ exercício da criatividade, desenvolvimento das capacidades por meio de leitura, investigação, experimentação, interação com o meio ambiente e resolução de problemas integrando assim o conhecimento adquirido com a realidade vivida.

As publicações científicas da área estudam as características das práticas pedagógicas e as tendências de Educação Física que professores têm usado para planejarem os conteúdos de suas aulas com o objetivo de construírem perspectivas que transcendam as práticas mais voltadas para fins tecnicistas, como era mais visto até o fim dos anos 1970.

No entanto, apesar dos esforços realizados por diversos estudiosos em Educação Física para que haja uma mudança mais radical da prática pedagógica, ainda são observadas dificuldades dos professores em compreender como aplicar as novas tendências pedagógicas, mudar comportamentos tradicionais, assim como implantar conhecimentos 
desenvolvidos no âmbito acadêmico para a formação profissional (ANTUNES et al. 2005). Este distanciamento entre a produção de conhecimento e a prática pedagógica tem sido alvo de debate na área (TANI, 2007; GIMENEZ; CORREIA, 2015).

Mesmo não sendo exclusivamente uma característica da cultura brasileira, a baixa produção científica destinada à área escolar contribui para esse distanciamento. Embora tenha aumentado, o valor das publicações em percentual é de 16,20\%, conforme dados computados entre 2006 e 2012 por meio dos artigos publicados em oito (08) revistas correspondentes aos estratos A e B da Capes (WIGGERS, 2015).

Percebemos que no processo de formação profissional há uma cultura de conduta reiterando uma atitude de encarar o conhecimento de forma enciclopédica, mnemônica, repetitiva e reprodutora de "receitas" e rotinas sem esclarecimento de significado. Nela, os alunos assumem um papel passivo, com ausência de tomada de decisão gerando um sentimento de cansaço, saturação e desmotivação. Este quadro, sem sombra de dúvida, contribui para o abandono da área ou para o desenvolvimento de propostas que simplesmente reproduzam práticas desenvolvidas há muito tempo (GIMENEZ; CORREIA, 2015).

Outro fator preocupante diz respeito aos próprios cursos de formação profissional que, da forma como estão organizados, não vão ao encontro das demandas dos mais variados contextos de atuação dos profissionais. Isto aconteceria pelo distanciamento entre a produção de conhecimento e os cursos de Licenciatura, bem como, pela própria lógica linear que permeia a formação (GIMENEZ; SILVA, 2014).

Em face deste cenário, dar voz ao aluno poderá proporcionar uma visão que não estamos acostumados, uma vez que enfocará aspectos centrais da formação cidadã, permitindo conhecer os significados da experiência, as quais, muitas vezes, desde os anos iniciais de escolarização estimularam predominantemente as emoções de medo, vergonha, insegurança e temor (MEDINA; MEGÍAS; ARCOS, 2013).

Especificamente, essas formas de produção de conhecimento em Educação Física, relacionada com o campo da atuação pedagógica, vêm sendo construídas desde os anos 1980 e organizadas em dois agrupamentos: matriz teórica e matriz pedagógica, sendo esta última mais bem compreendida como prática social de intervenção. Para os autores, necessariamente, esse pensamento pressupõe o debate teórico-epistemológico ocorrendo com o sentido de superar a crise de identidade da área e a dicotomia teoria-prática, processo que caracterizou o campo de atuação profissional como dinâmico e reflexivo.

Nessa direção, também, a formação de professores passou a ser constituída por meio de atitude investigativa, desenvolvendo estudos sobre e para a prática pedagógica, visando, dessa forma, poder contribuir na solução de problemas educacionais vivenciados no cotidiano escolar (BETTI; ZULIANI, 2002; BETTI，2005，2007; BETTI; FERRAZ; DANTAS, 2011).

Pensar a formação de professores de maneira científica e contextualizada significa buscarmos superar a indicação realizada por Celante (2011), a qual afirma que os professores de educação física constroem sua prática pedagógica independentemente do conhecimento científico que tiveram acesso na formação profissional, caracterizando assim uma prática docente com perfil de imediatismo pedagógico decorrente da urgência na aplicação das aulas. Ferraz e Correia (2012) ratificam essa ideia de superação por meio da construção do conhecimento científico sobre a prática pedagógica quando destacam a importância do desenvolvimento de estudos a partir do contexto "intramuros", possibilitando a compreensão da escola como um universo de experiências e produção de saberes.

Concomitantes ao processo acadêmico de construção de conhecimento e formação de professores existem iniciativas governamentais preocupadas com a organização da prática pedagógica em Educação Física. Stein e Marin (2012), por exemplo, afirmam que a elaboração das Diretrizes Curriculares Nacionais (DCN/SES, 2004) foi realizada em 20 estados brasileiros e a aplicação dos conteúdos é obrigatória para os professores. Entretanto, a distância entre o processo de elaboração das propostas e a aplicação das mesmas pelos professores tem gerado tensões, pois a formação profissional tradicional observada nos cursos de graduação aliada à ideia de uma prática pedagógica baseada em um saber "prático" tem contribuído para a não legitimidade do documento oficial.

É interessante observarmos as incoerências geradas a partir da inconsistência dos argumentos apresentados pelos professores, pois para aqueles que desejam um referencial possível de imediata aplicação, as propostas curriculares se caracterizam exatamente como o modelo a ser seguido. No 
entanto, como elas estão "grávidas" das discussões acadêmicas ocorridas nas últimas décadas e possuem a imposição do Estado, acabam gerando um movimento de resistência em uma parcela do professorado.

Algumas iniciativas têm sido realizadas e descritas pela literatura, como é o caso estudado por Rocha e Daolio (2014). Os autores analisaram a prática docente na rede pública do estado de São Paulo e constataram que existem modificações sensíveis na prática pedagógica. Essas mudanças estariam associadas à aplicação da proposta curricular, à compreensão do documento por parte dos professores e a sua respectiva relação com os alunos. De modo geral, eles defendem que é por meio do conflito que se construirá uma prática pedagógica, e assim os avanços acontecerão.

Outro ponto de vista sobre o processo de construção das propostas curriculares é o estudo de Tenório et al. (2012). O trabalho desses autores teve como objetivo verificar a coerência entre a intencionalidade e avaliação dos documentos apresentados pelos estados brasileiros da região sudeste. Para eles, diferente do currículo, a proposta curricular é mais específica no que se refere à dimensão operacional e possui uma relação mais próxima com o projeto político pedagógico da escola expressando elementos do contexto histórico, intencionalidade (englobando objetivos, habilidades e competências), conteúdos, aspectos metodológicos e avaliação. Eles identificam que na organização da maioria das propostas estudadas a intencionalidade e avaliação se caracterizam como estruturantes e, por esse motivo, são adotadas como objeto de estudo. Os autores destacam a falta de clareza em algumas propostas, ou então, enfatizam a existência de programas que foram orientados por uma tendência mascarada de colaborar com a ideia mercadológica do ensino para atender aos sistemas de avaliação da educação básica e exame nacional do ensino médio (ENEM).

Entretanto, é inegável que a área Educação Física escolar vem buscando sustentar sua atuação no campo educacional por meio de práticas que modifiquem a lógica técnica da execução dos movimentos, fato que tem apontado para a necessidade de atuar no campo da escolarização de modo a atender as necessidades dos alunos para uma compreensão de mundo diferenciada em relação ao senso comum e, dessa forma, contribuir para uma formação cidadã.

Alguns estudos apontam para uma nova época, a partir das discussões conceituais da área mais voltadas para o propósito de exploração das práticas corporais no âmbito escolar, pois uma vez que o avanço na determinação do objeto de estudo e possibilidades de abordagem dos conteúdos estão claramente estabelecidos, embora não haja consenso e, possivelmente, nem deverá haver, é momento de estudarmos a implantação destas ideias no contexto escolar, bem como avaliar as formas de operacionalização desses conteúdos por parte dos professores e os impactos provocados na aprendizagem dos alunos (CORREIA, 2010, 2014; DINIZ; GIMENEZ, 2016).

Dentre esses estudos é possível destacar alguns trabalhos que remetem às representações sociais que estudantes do Ensino Fundamental e Médio apresentam em relação ao componente curricular Educação Física (DEVIDE; RIZZUTI, 2001; DARIDO, 2004; PEREIRA, 2008). São identificados ainda, estudos dedicados a investigação das representações sociais sobre alguns conteúdos específicos da Educação Física, como é o caso da questão do gênero na Dança, entre estudantes do Ensino Superior (FINCK; CAPRI, 2011).

Todavia, corroborando os estudos sobre a produção científica da área escolar, pode ser considerada escassa a literatura que tem investigado a forma como os alunos concebem os conteúdos da Educação Física Escolar. É fato que, durante os últimos dez anos, o foco atribuído a esses conteúdos por parte do governo do Estado de São Paulo foi consideravelmente ampliado. Contudo, ainda não está devidamente esclarecido o quanto esta tendência tem proporcionado de desdobramentos na visão dos alunos.

Sendo assim, o presente estudo se propôs a analisar o contexto escolar, no qual o professor de educação física tem trabalhado utilizando a orientação dos referenciais curriculares do estado de São Paulo, visando verificar o impacto da prática pedagógica sobre o conhecimento declarativo dos alunos do $9^{\circ}$ ano do Ensino Fundamental II a respeito do Se-movimentar na Cultura de Movimento, seus significados/sentidos e intencionalidades.

\section{Metodologia}

Os procedimentos desta pesquisa caracterizaram-se, quanto ao tipo, como uma combinação de pesquisa bibliográfica e exploratória, supondo o estabelecimento do referencial teórico e a observação do pesquisador em instituição de ensino (LAKATOS, 1987). 
Toda a trajetória do raciocínio científico, também caracterizado como método de abordagem, foi realizada com base nos princípios da Teoria dos Sistemas Complexos. O modo pelo qual os procedimentos foram realizados caracterizou a pesquisa como Qualitativa ou InterpretativoIdealista. Isto significa que o estudo em sua intenção foi descritivo e possuiu, como verdadeiro propósito, buscar uma compreensão interpretativa seguindo os aspectos propostos pela taxionomia de Santos Filho (2001). São eles: a) Visão de mundo ou premissas subjacentes - entende a verdade como relativa e subjetiva, reconhecendo a mudança e aceitando a teoria do conflito; b) Relação entre o pesquisador e o objeto pesquisado - o dualismo é inaceitável, ou seja, é impossível o investigador e o processo de pesquisa não influenciarem o que é investigado; c) Relação entre fatos e valores - devese abandonar a ficção da neutralidade e assumir a consideração dos valores da pesquisa como um fator positivo e não negativo; d) Objetivo da pesquisa - é preciso tentar entender o significado que os outros dão às suas próprias situações por meio de uma compreensão interpretativa da linguagem, gestos etc.; e) Abordagem - o estudo qualitativo protótipo é o etnográfico, que ajuda o leitor a compreender as definições da situação das pessoas que são pesquisadas; f) Foco - é a experiência individual de situações, o processo de construção do significado, o "como"; g) Método - opta-se pelo método indutivo, por definições que envolvem o processo e nele se concretizam pela intuição e criatividade durante o processo da pesquisa, por conceitos que se explicitam via propriedades e relações, pela síntese holística e análise comparativa e por uma amostra pequena escolhida seletivamente; h) Papel do pesquisador - imergir-se no fenômeno de interesse; i) Principal critério de pesquisa - a validade é o mais importante.

Dessa maneira, para todo o modo exploratório da investigação, também caracterizado como modo de observação que "constitui o meio de abordagem do real", fixando "o quadro instrumental de apreensão dos dados", utilizado foi o método descritivo por meio da técnica de pesquisa "Survey" eletrônico (THOMAS; NELSON; SILVERMAN, 2012).

Para tanto, participaram do estudo 52 alunos e alunas regularmente matriculados no ensino fundamental II da escola pública do Estado de São Paulo Professora Jussara Feitosa Domschke no ano de 2015, localizada no município de Suzano. A coleta das respostas foi realizada no retorno às aulas do primeiro semestre de 2016, anterior ao início das atividades do semestre letivo, pois, desse modo, poder-se-ia avaliar o conteúdo retido na memória dos alunos após o período de férias.

As técnicas utilizadas no desenvolvimento da pesquisa, aqui entendidas como procedimentos mais restritos e mais concretos que operacionalizam os métodos, servindo-se de instrumentos, foram: a) Pesquisa Bibliográfica - Levantamento inicial das obras relativas aos termos-chave do trabalho; Seleção de obras por meio de análise textual; Aprofundamento das obras selecionadas por meio de análise temática, análise interpretativa e problematização; Definição das categorias iniciais a serem utilizadas na pesquisa exploratória; b) Pesquisa Exploratória - Escolha do local para a coleta dos dados foi não probabilística, intencional realizada por meio de contato prévio com a escola; Solicitação de permissão dos pais para que seus filhos e filhas pudessem participar da pesquisa por meio do recolhimento do Termo de Consentimento Livre e Esclarecido; Aplicação de questionário eletrônico contendo perguntas abertas, as quais foram respondidas pelos (as) alunos(as) no Laboratório de Informática da Escola sob a supervisão do funcionário responsável pelo setor, de forma individual e sigilosa.

O conteúdo do questionário visou conhecer o impacto provocado pelas aulas no conhecimento declarativo dos alunos do Ensino Fundamental II sobre as aulas de educação física, tendo em vista os documentos: Currículo do Estado de São Paulo: linguagens, códigos e suas tecnologias (2012) e Proposta Curricular do Estado de São Paulo: Educação Física (2008).

O trabalho foi submetido e aprovado pelo Comitê de Ética da Universidade Cidade de São Paulo, durante o ano de 2016, conforme parecer n.1.510.618.

A análise da coleta de informações foi feita por meio da identificação dos conteúdos presentes nas respostas abertas, constituindo categorias de análise e após isso foi aplicada estatística descritiva (cálculo de frequência e porcentagem). O estabelecimento das categorias seguiu o procedimento proposto por Velasco e Diaz de Rada (1997, p. 41-72), o qual é constituído de quatro momentos que se expressam, geralmente, do seguinte modo: Descrição - processo de elaboração dos dados considerados mais primários e mais diferenciados procurando estruturas de significação, captando a variedade de significados tornando-os acessíveis e situando o ponto de vista dos "atores"; 
Tradução - transcrever de forma crítica e interpretativa a experiência descrita nas categorias, reconhecendo valores do conhecimento declarado em função dos conteúdos propostos; comparar as descrições feitas; Explicação - toda explicação contém dois tipos de proposições: 1) explanadora uma proposição que descreve o fenômeno mediante dados observáveis e 2) expressiva - proposições que dão conta do fenômeno, expressam leis e condições iniciais ou antecedentes do fenômeno; Interpretação - descobrir a ordem estrutural de modo que resulte compreensível: 1) buscar relações nas quais a descrição em profundidade acabe sendo uma composição hipotética da cultura tal qual como a vê o pesquisador; 2) identificar temas, mostrar sua vinculação, expor o conjunto de regras e construir as estruturas simbólicas subjacentes.

\section{Resultados}

TABELA 1: Declaração sobre o conhecimento do que são: jogo, esporte, ginástica, luta, atividade rítmica e exercício físico.

\begin{tabular}{l|rr}
\hline Categoria & Frequência & Porcentagem \\
\hline Atividades físicas & 09 & 17,3 \\
Estimular o corpo & 02 & 3,8 \\
Exercícios físicos & 07 & 13,5 \\
Expressão & 02 & 3,8 \\
Lazer & 03 & 5,8 \\
Movimentos corporais & 07 & 13,5 \\
Saúde & 13 & 25,0 \\
Não compreendeu & 19 & 36,5 \\
\hline
\end{tabular}

$\mathrm{Na}$ Tabela 1 observamos um alto percentual $(36,5 \%)$ indicando a não compreensão sobre os conceitos do que são as práticas corporais. É possível que esse resultado seja decorrência da leitura e interpretação da questão, mas, também, pode ser que para esses alunos os aspectos conceituais não estejam obtendo significado naquilo que se refere à essência do se-movimentar. No entanto, quando somadas às categorias atividades físicas, exercícios físicos e movimentos corporais totalizam $44,3 \%$, fato que, mesmo de modo difuso, pode ser considerado indicativo de uma visão geral sobre a Cultura de Movimento. Como podemos ler na resposta da aluna 12: "São atividades que de fato trabalham o nosso corpo, como, por exemplo, o exercício físico, o esporte, a ginástica, a luta e a atividade rítmica. Mas elas não só trabalham o nosso corpo como a nossa mente como o jogo, que temos que criar estratégias". (Grifo nosso).

Por outro lado observamos algumas respostas detalhando uma compreensão mais voltada para o como se executa o movimento ou então para os impactos que as práticas corporais podem proporcionar. Isso pode ser constatado por meio do percentual atribuído à saúde $(25,0 \%)$ ou pelas respostas dos alunos: (06) "jogo pode ser usado para o futebol, basquete e coisas jogadas em grupo ou individualmente e futebol, basquete, tênis de mesa e etc... a ginástica para deixar nosso corpo mais flexível e ágil a luta para deixar-nos, mais espertos competir em campeonatos e ganhar faixas, atividade rítmica para praticarmos exercícios com fitas e etc... exercício físico para ficarmos saudáveis".(41) "São atividades físicas que usam praticamente toda região corporal, no ato de exercitar as partes corporais $e$ fisiológicas".(46) "para mim são 6 tópicos a qual você usa muito o seu corpo pra fazer certos movimento físicos, como, resistência, flexibilidade ,força".

Essa visão ficou mais marcada quando perguntado sobre a justificativa do praticar o semovimentar. A Tabela 2 mostra que $63,5 \%$ das respostas indicaram para uma saúde melhorada seguida, de longe, pelas categorias: evitar o sedentarismo (11,5\%); prevenir lesão $(7,7 \%)$; controlar peso/obesidade $(5,8 \%)$; condicionamento físico $(3,8 \%)$, as quais, também, têm o mesmo sentido. Apenas 5,8\% indicaram a diversão como uma justificativa da prática corporal. Esses dados indicam para uma perspectiva de saúde predominante no conhecimento declarativo desses alunos, que é confirmada quando detalhamos seus discursos.

A aluna 8 se justificou da seguinte maneira: "Na minha opinião.... sempre é bom indicar essas 
formas de movimentos, porque esses exercícios fazem muito bem para nossa saúde, e sempre é bom estar praticando essas atividades físicas para sempre ter um corpo em boa forma etc...". Sua colega (12) respondeu o seguinte: "Porque é importante para a nossa saúde, o nosso corpo precisa de exercício por inúmeras razões. Como, por exemplo, evita o sedentarismo, uma doença que afeta nossa população, principalmente os jovens. $O$ Sedentarismo causa a obesidade, enfraquecimento dos ossos, e principalmente problemas respiratórios".

TABELA 2: Declaração sobre porque é indicado praticar as formas de se-movimentar.

\begin{tabular}{l|rr}
\hline Categoria & Frequência & Porcentagem \\
\hline Condicionamento físico & 02 & 3,8 \\
Controlar o peso/Obesidade & 03 & 5,8 \\
Diversão & 03 & 5,8 \\
Evitar o sedentarismo & 06 & 11,5 \\
Falta de clareza & 04 & 7,7 \\
Melhorar a saúde & 33 & 63,5 \\
Necessidade de movimentar o corpo & 04 & 7,7 \\
Prevenir lesão & 04 & 7,7 \\
\hline
\end{tabular}

É interessante ressaltarmos que quando eles declararam, na Tabela 3, opinião sobre os espaços onde a prática pode ser realizada houve uma indicação para a ocupação de espaços dos mais diversos tipos, não se limitando ao espaço privado, como academias, clubes etc., mas sim percebendo a possibilidade de uso dos espaços públicos como parques, praias e ruas tornarem-se locais propícios para o se-movimentar.

TABELA 3: Declaração sobre onde podem ser praticadas as formas de se-movimentar.

\begin{tabular}{|c|c|c|}
\hline Categoria & Frequência & Porcentagem \\
\hline Academias & 11 & 21,2 \\
\hline Campo; parque; rua; praia & 19 & 36,5 \\
\hline Casa & 05 & 9,6 \\
\hline Escola (pátio, sala de aula, quadra) & 09 & 17,3 \\
\hline Falta de clareza & 02 & 3,8 \\
\hline Ginásios e quadras & 13 & 25,0 \\
\hline Lugares amplos/Aberto & 04 & 7,7 \\
\hline Lugares apropriados/adequados & 12 & 23,1 \\
\hline Qualquer lugar & 10 & 19,2 \\
\hline
\end{tabular}

Essa noção sobre a ocupação dos lugares sem prévio desígnio fica clara ao considerarmos as respostas "lugares amplos/abertos", "lugares apropriados/adequados" e "qualquer lugar". Juntas essas categorias somam 50,0\% de respostas. Mesmo não havendo clara indicação por meio das respostas, esse fato pode ser interpretado como uma perspectiva cidadã de empoderamento daqueles que percebem a possibilidade de ocupar os espaços da cidade para a finalidade que mais bem atender sua necessidade. As respostas de dois alunos (04 e 30) e uma aluna (12) entendem poder ser: "em escolas ruas parques onde der para fazer as atividades". Sua colega (12) diz: "Na escola, em casa mesmo ... claro se o lugar for próprio para isso. Em academias, parques ... etc". "em áreas de lazer como parques, quadras, campos e etc". (Grifo nosso).

$\mathrm{Na}$ Tabela 4, novamente voltou com muita veemência à questão da saúde. Perguntados sobre o objetivo do se-movimentar, mais de $70 \%$ afirmaram serem os aspectos: controlar a obesidade, evitar o sedentarismo, melhorar a condição física e melhoria da saúde as finalidades das práticas corporais. 
TABELA 4: Declaração sobre para quê servem as formas de se-movimentar

\begin{tabular}{l|rr}
\hline Categoria & Frequência & Porcentagem \\
\hline Controlar a obesidade & 01 & 1,9 \\
Evitar o sedentarismo & 03 & 5,8 \\
Falta de clareza ou não respondeu & 10 & 19,2 \\
Melhorar a condição física & 06 & 11,5 \\
Melhoria da saúde & 27 & 51,9 \\
Ocupar o tempo & 02 & 3,8 \\
Participar em campeonatos & 01 & 1,9 \\
Saber jogar/lutar & 02 & 3,8 \\
\hline
\end{tabular}

Assim declarou a aluna 12 em sua resposta: "Essas (formas de se-movimentar) serve para melhorar a nossa saúde, deixar o nosso corpo mais saudável. Serve para todos aqueles que têm interesse em ter uma saúde estável e bem equilibrada". Importante destacar que houve ampliação do conceito de saúde atingindo o bemestar psicológico, fato observado na resposta da aluna 42: "essas formas de se movimentar servem pra muita coisa, como ajudar a combater doenças e servem para melhorar a auto estima de uma pessoa". E até mesmo, discretamente, chegando a pensar aspectos sociais que podem ser vistos próximos do que a área do Lazer disse: "para pessoas que tenham interesse em atividades físicas e para quem quer manter sua saúde boa, para melhorar sua saúde, passar o tempo" (resposta da aluna 49 , grifo nosso).

Embora entendamos que haja possibilidade de interpretação, verificamos que não houve permanência dessa visão mais ampliada quando responderam sobre a finalidade em relação a quem pratica o se-movimentar. Mesmo considerando, poder ter havido falta de compreensão devido a formulação da questão que colocou juntas as ideias de "para que servem" e "para quem servem", e isso confundiu a leitura e interpretação dos alunos. A Tabela 5 mostra uma redução da visão dos alunos sobre quem pode usufruir das práticas corporais. Em $50,0 \%$ das respostas, houve "falta de clareza ou não responderam", $25,0 \%$ responderam "todas as pessoas", $13,5 \%$ disseram serem os "sedentários" a finalidade que, mesmo somados aos $3,8 \%$ das "pessoas obesas" e, também, 3,8\% das "pessoas com problemas de saúde", não atingem mais que $22,0 \%$ do total das respostas.

TABELA 5: Declaração sobre para quem servem as formas de se-movimentar.

\begin{tabular}{l|rr}
\hline Categoria & Frequência & Porcentagem \\
\hline Falta clareza ou não respondeu & 26 & 50,0 \\
Jogadores/Praticantes de esporte & 02 & 3,8 \\
Pessoas com problemas de saúde & 02 & 3,8 \\
Pessoas obesas & 02 & 3,8 \\
Sedentários & 07 & 13,5 \\
Todas as pessoas & 13 & 25,0 \\
\hline
\end{tabular}

Considerando que até aqui as respostas declararam uma percepção com tendência diferenciada sobre o papel da Educação Física no contexto escolar e isso já seria indicativo de que mudanças estão acontecendo, caminhamos para tratar das questões que envolvem a declaração sobre o aprendizado tangível que estabelece a partir do "chão da quadra" conhecimentos tácitos específicos da Cultura de Movimento.

A Tabela 6 apresenta as respostas sobre os conhecimentos declarados pelos alunos referentes à sua aprendizagem, ou seja, aquilo que tem encarnação e constituirá a pessoa que vivenciou esses conteúdos nos mais diferentes campos que vir a ocupar. Nesse sentido, mesmo que tenha sido declarada a categoria "regras do futebol" como a mais predominante $(25,0 \%)$, isso apareceu com outra concepção e muitas outras possibilidades de conhecimento apareceram no discurso dos alunos e alunas. Isso é algo para observarmos com mais cuidado. Nesse sentido, um dos depoimentos destacados (aluna 17) declarou sobre o conteúdo futebol o seguinte: "futebol, as regras foram os próprios alunos que criam, as regras foram parecidas com as de um jogo de futebol de verdade, como, falta, pênalti, bola fora da área etc, e com 
isso podemos aprender a trabalhar em grupo". Quando imaginaríamos nos anos passados que uma menina declarasse algo sobre esse conteúdo? Outra vez a interpretação nos leva a pensar nas discussões sobre gênero que perpassam a prática pedagógica daqueles que hoje buscam transcender a "prática pela prática".

TABELA 6: Declaração dos conhecimentos aprendidos sobre: princípios técnico e tático, principais regras e processo histórico

\begin{tabular}{|c|c|c|}
\hline Categorias & Frequência & Porcentagem \\
\hline Beisebol & 02 & 3,8 \\
\hline Capacidades físicas & 05 & 9,6 \\
\hline Ginástica/Exercício físico & 03 & 5,8 \\
\hline Golpes de Capoeira & 04 & 7,7 \\
\hline Nada & 01 & 1,9 \\
\hline Não lembro & 06 & 11,5 \\
\hline Não sei & 02 & 3,8 \\
\hline Princípios técnicos do Futebol & 02 & 3,8 \\
\hline Princípios técnicos do Voleibol & 01 & 1,9 \\
\hline Processo histórico & 01 & 1,9 \\
\hline Processo histórico/Origem do Caratê & 02 & 3,8 \\
\hline Processo histórico/Origem do hip-hop & 03 & 5,8 \\
\hline Regras da Capoeira & 01 & 1,9 \\
\hline Regras da Ginástica Rítmica & 01 & 1,9 \\
\hline Regras do Futebol & 13 & 25,0 \\
\hline Regras do Voleibol & 02 & 3,8 \\
\hline Regras dos esportes & 08 & 15,4 \\
\hline Sistemas táticos & 07 & 13,5 \\
\hline Sistemas táticos do Futebol & 06 & 11,5 \\
\hline Sistemas táticos do Handebol & 03 & 5,8 \\
\hline Sistemas táticos do Basquetebol & 02 & 3,8 \\
\hline
\end{tabular}

Além disso, a declaração do conhecimento sobre a Cultura de Movimento proporcionando a interação com as formas de manifestação social das práticas corporais chamou a atenção quando os alunos declararam: (30) "eu lembro sobre o futebol, que tinha varias técnicas como 4-4-2. As regras principais são cobrar lateral com as mãos". (33) "Me recordo dos sistemas táticos do handebol, futebol, futsal e vôlei, também me recordo do processo histórico do futebol, que veio ao Brasil pelo Charles Muller. Me recordo das regras do futebol e futsal, basquetebol e vôlei, onde no vôlei cada time marca ponto quando a bola tocar o chão na área do time adversário. etc...". (41) "Lembro dos princípios técnicos do: Voleibol, futebol, capoeira e handebol. Um dos princípios seria do futebol que leva a concentração defensiva $e$ a cobertura ofensiva". Todos esses alunos declararam ter ido além do aprender a fazer para aprender a conhecer sobre a Cultura de Movimento. E declararam a emoção vivida na aula que, não sabemos por quanto tempo, os acompanhará na vida: "futebol, as regras são as mesma de todos jogos de futebol, eu me lembro que fiz 2 gols", (aluno 48). (Grifo nosso).

A diversidade dessas experiências é apresentada na Tabela 7, na qual os alunos e alunas declararam as relações que estabeleceram entre as práticas corporais e outras dimensões do conhecimento sobre Educação Física.

Podemos observar que houve uma pulverização das respostas, as quais, mesmo tendo tendências para um olhar de saúde, declararam visões sobre estética e/ou aparência, diversão, expressão, jogo etc. Questões essas que estão presentes nas orientações curriculares propostas pelo Estado. A aluna 12 declarou: "Que todos eles deixam a nossa saúde estável e se forem praticados com mais frequência e compromisso podem também deixar a nossa aparência física mais bonita. Ginástica, luta e esporte praticados com cuidado e do modo certo, deixam a nossa aparência física mais saudável, pois nos fazem ganhar massa muscular, mas eles também deixam a nossa aparência física mais jovem". O aluno 19 considerou alguns aspectos filosóficos: "todo 
esporte, ginástica, atividade rítmica e exercício físico ajuda na nossa saúde porem qualquer atividade em excesso pode prejudicar o nosso corpo fisicamente, na questão de beleza isto no esporte apenas considerado ética". (Grifo nosso).

TABELA 7: Declaração sobre quais relações podem ser feitas entre jogo, esporte, ginástica, luta, atividade rítmica e exercício físico e os conhecimentos sobre as capacidades físicas, corpo, saúde e beleza

\begin{tabular}{l|rr}
\hline Categoria & Frequência & Porcentagem \\
\hline Academia & 01 & 1,9 \\
Academia para estética & 02 & 3,8 \\
Academia para saúde & 01 & 1,9 \\
Ajudam a ter saúde & 11 & 21,2 \\
Ajudam o corpo & 08 & 15,4 \\
Aparência melhor/mais jovem & 03 & 5,8 \\
Aparência física saudável & 02 & 3,8 \\
Capacidades físicas & 02 & 3,8 \\
Cuidados com o corpo & 03 & 5,8 \\
Estar em forma & 02 & 3,8 \\
Estética & 04 & 7,7 \\
Falta clareza & 05 & 9,6 \\
Jogo como forma de diversão & 04 & 7,7 \\
Jogo como forma de expressão & 02 & 3,8 \\
Não sei & 03 & 5,8 \\
Prática de esportes para estética & 03 & 5,8 \\
Prática de esportes para saúde & 07 & 13,5 \\
Saúde & 05 & 9,6 \\
Saúde e beleza auxiliam na prática de esportes & 01 & 1,9 \\
\hline
\end{tabular}

Essa tendência se confirmou quando verificamos as declarações sobre as relações entre Educação Física, gênero, família, preconceito étnico-racial, amigos e comunidade descritos na Tabela 8.

Vejamos essa confirmação por meio das declarações ditas pelos alunos e alunas a esse respeito: "que você pode conhecer pessoas novas $e$ ter amizades talvez para a vida toda e aprende a não ter preconceitos com a cor ou dificuldade do amigo" (aluno 6). "Que muitos pais, incentivam os filhos de certa forma a praticarem atividades físicas, os mais procurados são Futebol, Vôlei, Natação. Com os diversos programas que estão sendo oferecidos nas comunidades, essas pessoas que vivem nela tem mais acessibilidade com o esporte" (aluna 12). "Esporte pode fazer a diferença em muitos lugares, como o futebol por exemplo que salva muitos jovens de comunidades de entrar em um mundo ruim, as vezes ajuda ate combater preconceito" (aluno 19). "Um jogo, um esporte tem uma grande relação com a família, amigos, $e$ comunidade, pois quando se tem um lugar em uma vila onde os jovens podem praticar esses exercícios físicos as pessoas tende a ficar mais unidas e criar novas amizades, e quando a família incentiva uma pessoa a praticar essas modalidades ficam mais fáceis de seguir em frente fazendo o que faz" (aluna 42).

TABELA 8: Declaração sobre quais relações podem ser feitas entre jogo, esporte, ginástica, luta, atividade rítmica e exercício físico e os conhecimentos sobre gênero, família, étnico-racial, amigos e comunidade

\begin{tabular}{|c|c|c|}
\hline Categoria & Frequência & Porcentagem \\
\hline Acessibilidade & 01 & 1,9 \\
\hline Amigos e família & 06 & 11,5 \\
\hline Culturas diferentes/Outros países & 02 & 3,8 \\
\hline Diversão & 03 & 5,8 \\
\hline
\end{tabular}


Escola da família

Esporte como combate ao preconceito

Esporte como meio de evitar o envolvimento com drogas

Esporte em vários lugares

Falta clareza

Gênero

Incentivo à prática de atividades físicas

Manter seu corpo em forma

Movimentação do corpo

Nada

Não sei

Não ter preconceitos

Respeito com todos

São importantes

Socialização

Todos podem fazer

Trabalho em conjunto/grupo/cooperação

Os resultados e declarações indicaram que houve clara percepção de questões envolvendo os aspectos socioculturais do contexto vivenciado. Não sabemos o tempo de permanência dessas percepções, pois certamente dependerão das experiências que virão, mas é possível interpretar que, nesse momento descrito pela pesquisa, existiu uma consciência ampliada com condições de visualizar aquilo que é vivido nas aulas para além dos muros da escola.

A Tabela 9 reforça essa percepção de consciência social tendo em vista o que foi declarado referente às pessoas com deficiência. A possibilidade de consideração do processo de inclusão, como uma via de convivência entre semelhantes, ficou clara nos índices percentuais como nos depoimentos individuais.

TABELA 9: Declaração sobre quais relações podem ser feitas entre jogo, esporte, ginástica, luta, atividade rítmica e exercício físico e pessoas com deficiência

\begin{tabular}{|c|c|c|}
\hline Categoria & Frequência & Porcentagem \\
\hline Amizade e felicidade sem discriminação & 01 & 1,9 \\
\hline Aulas para cego, surdo e mudo & 01 & 1,9 \\
\hline Cuidado & 01 & 1,9 \\
\hline Esporte sem limites/Todos podem praticar & 04 & 7,7 \\
\hline Esportes ajudam na melhora/tratamento & 04 & 7,7 \\
\hline Esportes especiais/adaptados & 14 & 26,9 \\
\hline Falta clareza & 05 & 9,6 \\
\hline Faz bem a saúde & 06 & 11,5 \\
\hline Força de vontade/coragem & 02 & 3,8 \\
\hline Inclusão & 04 & 7,7 \\
\hline Melhora o relacionamento & 01 & 1,9 \\
\hline Não sei & 04 & 7,7 \\
\hline Paralimpíadas & 04 & 7,7 \\
\hline Possuem dificuldades, mas podem realizar & 02 & 3,8 \\
\hline Somos todos iguais & 02 & 3,8 \\
\hline
\end{tabular}

A aluna 12 declarou: "Hoje em dia, fazer exercícios físicos, jogos, esportes, ginásticas, luta e atividades rítmicas para pessoas com deficiência não é problema, pois com sua coragem de encarar o esporte eles conseguem fazer o esporte até melhor do que as pessoas que não tem nenhuma 
deficiência". A aluna 27 indicou: "Que independente ou não se a pessoa é deficiente ela é capaz de praticar, de uma forma especial mais tem". Já o aluno 40 afirmou: "as atividades fisicas foram feitas para todos nem que seja adaptado". E, por fim, a aluna 42 confirmou que: "uma pessoa que tem algum tipo de deficiência, uma paralisia, por exemplo, quando pratica algum exercício ajuda muito em um tratamento que essa pessoa possa supostamente estar fazendo, ou até mesmo, melhorar o humor ajudando a evitar depressão". $\mathrm{Se}$ observarmos as respostas dessa aluna perceberemos que houve uma consciência diferenciada sobre tantas "coisas" que envolvem a
Cultura de Movimento.

Finalmente, na tentativa de nos aproximarmos do mundo jovem que atualmente tem nos meios de comunicação e nas redes sociais uma via dinâmica de relacionamento e contato com o mundo, foi possível perceber que as declarações indicaram para uma forma rápida de comunicação e divulgação daquilo que é vivido nas experiências do se-movimentar. A Tabela 10 apresenta como principal item declarado a "divulgação de atividades esportivas", o que faz com que interpretemos que ainda não há percepção de outras formas de utilização dos meios de comunicação para ampliar os níveis de análise da Cultura de Movimento.

TABELA 10: Declaração sobre quais relações podem ser feitas entre jogo, esporte, ginástica, luta, atividade rítmica e exercício físico e os meios de comunicação (TV, rádio, jornal, internet, telefone celular, redes sociais etc.)

\begin{tabular}{l|rr}
\hline Categoria & Frequência & Porcentagem \\
\hline Aquisição de conhecimentos & 04 & 7,7 \\
Divulgação de atividades esportivas & 23 & 44,2 \\
Falta clareza & 05 & 9,6 \\
Fama/Jogadores famosos & 03 & 5,8 \\
Incentivo à prática de atividades esportivas & 03 & 5,8 \\
Informação & 04 & 7,7 \\
Interferência da mídia na formação de opinião do telespectador & 02 & 3,8 \\
Manipulação & 01 & 1,9 \\
Não sei & 05 & 9,6 \\
Sedentarismo causado pelo uso de redes sociais & 01 & 1,9 \\
Socialização através do esporte & 04 & 7,7 \\
\hline
\end{tabular}

A aluna 9 disse: "por que tudo que nos fazemos vai para as redes sociais, por exemplo na nossa escola temos um pagina na internet, por isso da para relacionar................. As perguntas não têm acento porque meu teclado estava com defeito a tecla não estava pegando". Na declaração da aluna, 12 identifica-se claramente a percepção das redes sociais no processo de divulgação de informação: "As redes sociais como facebook, instagram etc, estão ajudando muito a divulgar diversas atividade físicas que, de certa forma, podem servir como incentivo. $O$ Jornal pode mostrar as vitórias conquistadas pelos nossos atletas que representam $o$ nosso país". A aluna 16 "acenou" para uma percepção mais consciente sobre os meios de comunicação: "esporte passa no jornal, rádio, internet, ginástica passa na tv de vez em quando, luta passa de vez em quando também, atividade rítmica passa mais em tv, e exercício físico mais em redes sociais etc.". (Grifo nosso).

O aluno 19 declarou: "hoje em dia o esporte é algo de sucesso, nossa escola, por exemplo, quando participa de campeonatos, noticias são divulgadas na pagina da escola através da mídia o esporte vai ficando famoso e ganhando mais admiradores e mais pessoas começam a praticar $e$ ter uma vida melhor". E, novamente, a aluna 42: "a televisão, radio, jornal incentiva muito a uma pessoa pensar como eles, pois eles tentam mudar o jeito de olhar, tentam passar uma visão totalmente diferente do que realmente aconteceu ou, às vezes, tentam esconder alguma coisa, mais a internet é ainda pior, por conta das redes sociais, sempre quando tem jogo de futebol, vôlei, ou uma apresentação de alguma ginástica ou luta sempre alguém comenta do jeito deles do jeito que eles entenderam e, por isso, a mídia interfere muito nesses modos de se movimentar".

Horizontes, v. 36, n. 2, p. 57-12, mai./ago. 2018 
Portanto, compreendemos que as declarações realizadas pelos alunos e alunas proporcionaram contato mais próximo do que tem sido o cotidiano escolar daqueles preocupados com uma Educação Física contemporânea. Percebemos que as aulas de Educação Física têm proporcionado experiências que estimulam um nível de consciência diferenciado comparado ao que era o "modus operante" no modelo tradicional de trabalhar os conteúdos na escola. É essa percepção que se pretende discutir com aqueles ocupados em pensar a prática pedagógica da Educação Física na escola.

\section{Discussão}

Em artigo publicado em 2010, Betti et al. refletem sobre a proposta que realizaram para o estado de São Paulo e destacamos alguns pontos para iniciarmos essa discussão. O primeiro trata sobre a extensão do trabalho com os esportes na escola, que no entendimento dos autores deve transcender os estímulos e benefícios orgânicos, mas, principalmente, deve ser tratado como patrimônio histórico da humanidade e ser apreendido pelos alunos. O segundo diz respeito a consciência dos alunos e alunas sobre o conceito do Se-movimentar o qual, uma vez encarnado, proporciona uma percepção diferenciada sobre sujeito do movimento, consciente da própria identidade e subjetividade do movimento que realiza. Os temas que vão para além dos conteúdos tradicionais, também, são destacados como ponto de discussão. Preconceito racial, discriminação contra pessoas com deficiência, mídias e padrões de beleza são pontos importantes dessa prática docente proposta. As habilidades e competências para a constituição da autonomia foram objeto de destaque dos autores e entendemos que devam participar dessa discussão também.

Sobre o primeiro ponto dessa discussão, em nosso estudo, os resultados expostos nas tabelas como sínteses das declarações dos alunos e alunas participantes evidenciaram uma tendência para olhar o Se-movimentar mais voltado para a saúde. Esses dados corroboram a conclusão do estudo de Ulasowicz e Lomônaco (2016) que afirmam ser a saúde associada à atividade física uma forma de transcendência do ambiente escolar, uma vez que os alunos transformam as vivências da escola em predisposição e motivação para realizar as atividades fora da escola.

Os autores destacam que a formação do aluno para o exercício da cidadania compreende a motivação e a capacitação para o autocuidado. Eles entendem que a escola deva estabelecer elementos que capacitem os alunos para uma vida saudável, declarando compreensão sobre direitos e responsabilidades pessoal e social. Nesse sentido, as declarações ditas pelos alunos e alunas desse estudo indicaram para uma percepção, mesmo que não generalizada, de direitos de ocupação de espaços públicos para o Se-movimentar indicando percepções de direitos constitucionais, como é o caso do direito ao Lazer e empoderamento para sentir-se "proprietário" dos espaços comunitários (BRASIL, 1988).

Em linhas gerais a prática pedagógica proposta indica caminhar na direção de criar condições para que ocorra uma apropriação do patrimônio cultural por parte das crianças e jovens. Este patrimônio tangencia as questões do corpo associadas à estética e saúde (STEIN; MARIN, 2012). Em especial, esses temas estão sintonizados com as demandas sociais orientadas à busca por melhor qualidade de vida e por uma reavaliação dos valores estéticos associados ao corpo. Entendemos que essas percepções podem contribuir para os alunos e as alunas construírem sua identidade em busca de uma autonomia crítica e autocrítica.

Entretanto não foi possível percebermos essa tendência como a mais evidente quando analisados os resultados indicados pelas tabelas e pelos destaques das respostas apresentadas nesse trabalho. Pieroni e Corrêa (2011) destacam que o contato com o conhecimento conceitual das práticas corporais, por meio do caderno do aluno, permite perceber uma dimensão ainda não vivenciada pelo educando no que tange os conteúdos históricos e culturais e, desse modo, mais bem se apropriarem da Cultura de Movimento, o que possibilita atingir um estado maior de consciência sobre o Semovimentar. Temos que destacar não ter sido citado em momento algum pelos alunos e alunas dessa pesquisa o material "caderno do aluno" como uma via de acesso ao conhecimento. Esse fato pode ser um indicativo da baixa evidência nas declarações obtidas do sujeito como alguém consciente do próprio movimento.

Em parte, esta constatação é sustentada a partir dos dados que indicam uma predominância para as regras do futebol sobre conteúdos de natureza histórica e elementos de ética. Vale destacarmos que isto parece ocorrer, em que pese a existência de afirmações que sugerem a apresentação de conteúdos associados ao futebol, com contornos de debate e estímulo à discussão em 
grupo, como é o caso da própria dimensão de adaptação das regras. Esses achados corroboram os pressupostos levantados por Rocha e Daolio (2014) acerca da prática pedagógica dos professores de educação física.

Sobre os temas que extrapolam a tradição procedimental da Educação Física e constituem, atualmente, significativa parcela das produções científicas que estudam as práticas docentes, compreendemos que houve clara evidência nos depoimentos colhidos nessa pesquisa que ratificaram ser o conhecimento tratado nas aulas capaz de proporcionar percepções sobre questões tão importantes para a autonomia discente, e transcenderem os muros da escola, o que já fora dito por Von Zuben (1989) como função do processo de escolarização. Nesse sentido, os resultados e depoimentos selecionados para ilustrar o pensamento dos alunos e alunas indicaram para a mobilização das habilidades e competências destacadas por Betti et al. (2010) que são: identificar, relacionar, reconhecer, perceber, discriminar, comparar, analisar, selecionar, valorizar, compreender. Dessa maneira, compreendemos que poderão ser capazes de ascender aos níveis das competências mais complexas como: elaborar, avaliar, propor e apreciar (p. 115).

Logicamente não estamos propondo generalizações, mas sim a identificação de potencialidades estimuladas por meio de uma prática pedagógica comprometida com as tendências e propostas do pensamento acadêmico contemporâneo para a atuação no campo da Educação Física escolar. Nesse sentido, as interpretações indicaram que as constatações possíveis dessa pesquisa vão ao encontro do que Rezer (2015) sugeriu como aproximação do conhecimento didático-acadêmico e conhecimento aplicado para o enfrentamento dos desafios na área escolar de maneira mais apropriada. Por meio de aproximações mais qualificadas em Educação Física podemos constituir um corpo de conhecimentos que já não mais indica para uma dicotomia, mas sim caminha, passo a passo, para o que propunham as produções da área já no início dos anos 1980 e que até os dias de hoje ainda não se constituíram como uma cultura de prática pedagógica abrangente.

Compreendemos que este constitui um desafio considerável que permeia os cursos de formação profissional, tendo em vista a marcante influência de práticas tradicionalmente consolidadas e arraigadas em suas histórias de vida entre os estudantes de graduação, futuros profissionais da área (CELANTE, 2011). Tal fato nos remete à necessidade de se revisitar os modelos de formação profissional que têm sido adotados para a formação de professores de educação física (GIMENEZ; SILVA, 2014; GIMENEZ; CORREIA, 2015).

Esses autores argumentam em favor de uma necessidade de se analisar os programas de formação de professores a partir de concepções que envolvam a solução de problemas e que sejam concebidos por meio de uma ruptura de concepções famigeradas e dicotômicas entre teoria e prática, e básico e aplicado. Isto aconteceria, uma vez que se entende que, embora as DCN (DCN/SES, 2004) que permeiam a formação de professores de educação física apresentem um caráter suficientemente abrangente para a formação, os cursos ainda apresentam cunho predominantemente técnico e preso a modelos com tendências diretivas em suas práticas pedagógicas. Em outras palavras, entendemos que o impacto das propostas se torna limitado na medida em que os programas de formação profissional não buscarem revisitar suas propostas voltadas a professores da educação básica.

É oportuno destacarmos ainda que um efetivo empenho sobre as propostas desenvolvidas na educação infantil e no ensino fundamental I, visto a necessidade que uma articulação mais bem consolidada entre esses diferentes níveis da educação básica, poderia contribuir para mudanças mais concretas nas expectativas dos alunos em relação ao componente curricular educação física e o seu próprio corpo de conhecimentos sobre a área se tornar mais "encarnado".

Entendemos que este seja um possível caminho para uma mudança das próprias representações sociais relacionadas ao componente curricular Educação Física, uma vez que, conforme destacam Devide e Rizzute (2001), esta consolidação depende de mudança, pronunciadas na prática pedagógica dos professores.

\section{Considerações Finais}

Portanto, nesse estudo, partimos de um ponto de vista apresentado pela literatura sobre a baixa publicação da produção científica em Educação Física escolar para caminharmos em direção a algumas dessas publicações que apresentam denúncias e sugestões para a superação do "Status quo" deste componente curricular. Nesse movimento, avaliamos uma prática 
pedagógica preocupada com a transcendência das experiências vividas nas aulas e a permanência que essas vivências podem proporcionar aos alunos e alunas.

Em que pese à limitação da pesquisa, no que diz respeito à profundidade da análise e circunscrição do espaço no qual o fenômeno se expressou, procuramos tomar contato com o discurso de jovens estudantes que iniciavam o Ensino Médio em uma escola pública do estado de São Paulo para avaliar o que poderia ser declarado sobre a Cultura de Movimento vivenciada até o Ensino Fundamental II, tendo em vista a proposta realizada nessas aulas, em face das propostas previstas nas Diretrizes Curriculares do Estado de São Paulo (CNE/CES 7/2004).

Iniciativas como essa têm sido publicadas na área, e entendemos ser esse um "novo" momento das pesquisas educacionais ocupadas em demonstrar os impactos decorrentes do momento da crise de identidade vivida pela Educação Física no início dos anos 1980, na efetiva atuação daqueles professores e professoras preocupados com a qualidade de sua prática pedagógica e a possível transformação de seus alunos no sentido de se tornarem autônomos, críticos e autocríticos, ou seja, cidadãos.

Tomando os cuidados necessários para não confundirmos indícios com uma situação definida, as declarações analisadas nessa pesquisa apresentaram uma tendência a atender àquilo que tem sido proposto como papel da Educação Física no contexto escolar no que tange à percepção do que e para que serve o Se-movimentar. Mesmo se considerarmos o fato de dificuldade na compreensão dos alunos e alunas sobre os termos utilizados nas perguntas, ainda assim parece ser possível dizer que existiu pertinência para questões que envolvem a Cultura de Movimento.

A percepção das relações existentes entre o Se-movimentar e os temas emergentes, que é proposta para ser tratada pela Educação Física na escola, pareceu ter sido declarada, de modo que interpretamos uma discreta consciência da condição social ocupada por esses jovens e uma noção da necessidade de apropriação dos bens públicos para exercer o direito de usufruir da cidade. As declarações sobre mobilidade de pessoas com deficiência, discriminação étnico-racial e a influência da mídia na formação da consciência coletiva também sugerem esta preocupação e transição no pensamento na área.

De modo geral, esperamos ter contribuído com uma pequena parcela a ser somada a todo o trabalho necessário a ser feito, e que ainda está por vir, pois entendemos ser possível estruturar uma proposta de ensino e aprendizagem que objetive transcender o tradicionalismo em Educação Física escolar.

Por fim, sabedores das limitações do estudo, sugerimos que mais estudos se somem a esses que estão visando desenvolver esse "novo" tempo. Compreendemos que esse movimento se faz por decorrência do ingresso da "nova" geração de profissionais, a qual foi graduada a partir das discussões realizadas sobre a área, desde os anos 1980. Dada as dificuldades epistemológicas provenientes de todo processo de construção de conhecimento, reconhecemos a necessidade de ampliar e aprofundar as propostas educacionais em Educação Física, visando constituir um processo longitudinal e, porque não, legitimarmos nossas práticas pedagógicas e assim contribuirmos de maneira mais elucidativa para que alunos e alunas saibam mais bem dizer o que a Educação Física tem a contribuir para o processo de educação humana.

\section{Nota}

O presente artigo é a versão final do resumo apresentado no II Simpósio de Atividade Física e Saúde da Região Sudeste publicado pela Rev. Bras. Ativ. Fis. Saúde, 2016.

\section{Referências}

ANTUNES, F.H.C.; DANTAS, L.E.P.B.T.; BIGOTTI, S.; TOKUYOCHI, J.H.; TANI, G.; BRASIL, F.K.; ANDRÉ, M. Um retrato da pesquisa brasileira em educação física escolar: 1999-2003. Motriz, v. 11, n. 3, p. 179-184, 2005.

BETTI, M. Educação Física como prática científica e prática pedagógica: reflexões à luz da filosofia da ciência. Revista Brasileira de Educação Física e Esporte, v.19, n. 3, p. 183-97, 2005.

Educação Física e Cultura Corporal de Movimento: uma perspectiva fenomenológica e semiótica. Revista da Educação Física/UEM, v. 18, n.2, p.207-217, 2007.

BETTI, M.; DAOLIO, J.; VENÂNCIO, L.; SANCHES NETO, L. A proposta curricular de educação física do estado de São Paulo: 
fundamentos e desafios. In: CORREIA, W.R.; CARREIRA FILHO, D. (Orgs.). Educação Física escolar: docência e cotidiano. Curitiba: Editora CRV, 2010. p.179-191.

BETTI, M.; FERRAZ, O.L.; DANTAS, L.E.P.B.T. Educação Física escolar: estado da arte e direções futuras. Revista Brasileira de Educação Física e Esporte, v.25, p. 105-15, 2011.

BETTI, M.; ZULIANI, L.R. Educação Física escolar: uma proposta de diretrizes pedagógicas. Revista Mackenzie de Educação Física e Esporte, v.1, n.1, p.73-81, 2002.

BRASIL. Constituição Federal de 1988. Promulgada em 5 de outubro de 1988. Disponível em

http://www.planalto.gov.br/ccivil 03/constituicao/c onstituicao.htm. Acesso em: 15/06/2017

CELANTE, A. R. Notas sobre a pesquisa no cotidiano escolar acerca dos saberes na ação dos professores de Educação Física. In: GIMENEZ, R.; SOUZA, M. T. Ensaios sobre contextos da formação profissional em educação física. Várzea Paulista, SP: Fontoura, 2011. p.45-64.

CONSELHO NACIONAL DE EDUCAÇÃO. Câmara de Educação Superior. RESOLUÇÃO N ${ }^{\circ} 7$. Brasília, 5 de abril de 2004, Seção 1, p. 18.

CORREIA, W.R. Educação Física escolar: desafiando a sua presumível imutabilidade. Revista Brasileira de Educação Física e Esporte, v.28, n.4, p.691-700, 2014.

Educação Física no ensino médio: questões insólitas. In: CARREIRA FILHO, D.; CORREIA, W.R. (Orgs.). Educação Física escolar: docência e cotidiano. Curitiba: CRV, 2010, p.165-175.

DARIDO S.C. A Educação Física na escola e o processo de formação dos não praticantes de atividade física. Revista Brasileira de Educação Física e Esporte, v.18, n.1, p.61-80, 2004.

DEVIDE, F.P.; RIZZUTI, E.V. Transformações periféricas das representações sociais de alunos do ensino fundamental sobre a Educação Física escolar após intervenção pedagógica. Revista Brasileira de Ciências do Esporte, v.22, n.3, p.117-136, 2001.
DINIZ, L.T.; GIMENEZ, R. A construção do docente encarnado na experiência da ação corporal: perspectivas para a preparação profissional para a educação infantil. Horizontes, v.34, n.2, p.85-92, 2016.

FERRAZ, O.L.; CORREIA, W.R. Teorias curriculares, perspectivas teóricas em Educação Física escolar e implicações para a formação docente. Revista Brasileira de Educação Física e Esporte, v.26, n.3. p. 531-40, 2012.

FINCK, S.C.M.; CAPRI, F.S. As representações sociais da dança em aulas de educação física nos anos iniciais do ensino fundamental. Práxis Educativa, v.6, n.2, p.249-263, 2011.

GIMENEZ, R.; CORREIA, W.R. O ensino para a compreensão: considerações sobre a formação docente para a Educação Física na Educação Básica. Revista Brasileira de Educação Física e Esporte, v.29, n.9, p.9-17, 2015.

GIMENEZ, R.; SILVA, M.H.A. Formação de professores para a educação básica: revisitando concepções e práticas pedagógicas por meio do prisma de teorias da complexidade. Ambiente Educação, v.7, n.2, p.268-276, 2014.

LAKATOS, Eva Maria. Metodologia do trabalho científico. $2^{\text {a }}$ edição. São Paulo: Atlas, 1987.

MEDINA, B. M.; MEGÍAS, E. P.; ARCOS, D. P. La voz del alumnado: uma investigatión narrativa acerca de lo que siente, piensa, dice y hace el alumnado de Magistério de Educación Física en suformación inicial. Movimento, v.19, n. 04, p. 251269, 2013.

PEREIRA, G.M.S. Representações sociais de Educação Física: o resgate e o remédio do corpo e da mente. 2008. 115p. Dissertação (Mestrado em Educação). - Universidade Estácio de Sá, Rio de Janeiro, 2008.

PIERONI, C. B.; CORRÊA, D A. O currículo da educação física na Rede Estadual de Ensino de São Paulo: a perspectiva de educandos/as do ensino fundamental de uma escola na cidade de Bauru/SP. In: X Congresso Nacional de Educação EDUCERE: formação para mudanças no contexto da educação: políticas, Anais, v. 1, p. 7026-7039, 2011. 
REZER, R. Conhecimento, prática pedagógica e educação física: aproximações com o campo da didática. Movimento, v. 21, n. 3, p. 803-814, jul/set. 2015.

ROCHA, L.F.R.; DAOLIO, J. A prática pedagógica de educação física no currículo de São Paulo: espaço de tensão entre o tradicional e o novo. Pensar a Prática, v.17, n2, p.517-529, 2014.

SANTOS FILHO, J.C.; GAMBOA, S S. Pesquisa educacional: quantidade-qualidade. $4^{\mathrm{a}}$ edição. São Paulo: Cortez, 2001.

SÃO PAULO (Estado). Secretaria da Educação. Currículo do Estado de São Paulo: Linguagens, códigos e suas tecnologias. $2^{\mathrm{a}}$ ed. São Paulo: SE, 2012.

SÃO PAULO (Estado). Secretaria da Educação. Proposta curricular do Estado de São Paulo: Educação Física. São Paulo: SEE, 2008.

STEIN, F.; MARIN, E. C. A Educação Física nas propostas curriculares estaduais das regiões Sul e Sudeste. In: Seminário de Epistemologia e Teorias da Educação Anais Eletrônico (IV EPISTED).

Dezembro de 2012. Faculdade de Educação/Unicamp.

TANI, G. Avaliação das condições de ensino de graduação em Educação Física: garantia de uma formação de qualidade. Revista Mackenzie de Educação Física e Esporte, v.6, p.379-392, 2007.

TENÓRIO, K.M.R.; BEZERRA, B.B.; SOUZA JR,
M.; GOMES DA SILVA, P.N.; MELO, M.S.T. Propostas curriculares estaduais para a Educação Física: uma análise do binômio intencionalidadeavaliação. Motriz, v.18, n.3, p. 542-556, 2012.

THOMAS, J. R.; NELSON, J. K.; SILVERMAN, S. J. Métodos de pesquisa em atividade física. (Tradução: Ricardo Demétrio de Souza Petersen). $6^{\mathrm{a}}$ ed. Porto Alegre, RS: Artmed, 2012.

ULASOWICZ, C.; LOMÔNACO, J. F. B. A influência de um programa de ensino para a prática de atividades físicas nas aulas de educação física. In: SANCHES NETO, L.; FREIRE, E. S.; KERR, T. O.; VENÂNCIO, L. (Orgs.). Educação Física escolar e perspectivas de intervenção. (Vol. 7). Curitiba: CRV, 2016.

VELASCO, H. e DIAZ de RADA, A. La lógica de lainvestigación etnográfica: um modelo de trabajo para etnógrafos de laescuela. $2^{a}$ ediçãoInserir edição. Madrid: Editorial Trotta S.A., 1997.

VON ZUBEN, N. A. Sala de aula: da angústia de labirinto à fundação da liberdade. In: MORAES, R. (Org.). A sala de aula: que espaço é esse? 4. ed. Campinas: Papirus, 1989.

WIGGERS, I. D.; REIS, N. S.; TEIXEIRA E SILVA, L. T.; LIMA, M. M.; FREITAS, T. C.; PRAÇA, T. R. M.; FARIAS, M. J. A. Um "raio-x" da produção do conhecimento sobre educação física escolar: análise de periódicos de 2006 a 2012. Movimento, v. 21, n. 3, p. 831-845, jul/set., 2015.

\section{Sobre os autores}

Maurício Teodoro de Souza: Professor do curso de Educação Física da Universidade Cidade de São Paulo Mestrado e Doutorado pela FEF Unicamp.

Andréa Cristina Saitsu: Professora de Educação Física da rede pública estadual do Município de Suzano - SP Especialista em Psicopedagogia pela UNISUZ (Faculdade de Suzano - SP).

Roberto Gimenez: Professor do curso de Educação Física da Universidade Cidade de São Paulo e Professor do Programa de Mestrado de Educação da Universidade Cidade de São Paulo.

Submetido em agosto de 2017.

Aprovado em fevereiro de 2018. 